\title{
Association between the Presence of Class 1 Integrons, Virulence Genes, and Phylogenetic Groups of Escherichia coli Isolates from River Water
}

\author{
Ryszard Koczura • Joanna Mokracka • Agata Barczak • \\ Natalia Krysiak • Adam Kaznowski
}

Received: 2 November 2011 / Accepted: 23 July 2012 /Published online: 19 August 2012

(C) The Author(s) 2012. This article is published with open access at Springerlink.com

\begin{abstract}
Ninety-six class 1 integron-positive and 96 integron-negative Escherichia coli isolates cultured from the water of the Warta River, Poland, were characterized for their phylogenetic group affiliation and for the presence of genes associated with virulence. Most strains belonged to phylogenetic group A, but phylogenetic group affiliation was not related with the presence of integrons. The occurrence of heat-stable toxin gene of enterotoxigenic $E$. coli, $\mathrm{S}$ fimbriae subunit gene $s f a S$, and siderophore receptor genes, fyuA and iutA, was associated with the presence of class 1 integrons. Moreover, virulence factor score (the total number of virulence-associated genes) was associated with the presence of integrons in groups. The results bring new insight into relations between the presence of integrons in E. coli, virulence traits, as well as phylogenetic group affiliation.
\end{abstract}

\section{Introduction}

Escherichia coli is a part of intestinal flora of human and homoiothermal animals; however, pathogenic strains can cause gastrointestinal and extraintestinal infections. Strains that are responsible for gastrointestinal infections have been classified into several pathotypes, such as enteropathogenic $E$. coli (EPEC), enteroaggregative E. coli (EAEC), enterotoxigenic $E$. coli (ETEC), enteroinvasive $E$. coli (EIEC), diffusely adherent $E$. coli (DAEC), and Shiga toxin-producing E. coli (STEC), also referred to as enterohemorrhagic E. coli

R. Koczura $(\bowtie) \cdot J$. Mokracka • A. Barczak $\cdot$ N. Krysiak

A. Kaznowski

Department of Microbiology, Faculty of Biology,

Adam Mickiewicz University in Poznań,

ul. Umultowska 89,

61-614 Poznań, Poland

e-mail: koczma@amu.edu.pl
(EHEC). Major extraintestinal infections include mostly urinary tract infection, pyelonephritis, neonatal meningitis, cystitis, and bacteremia [1].

Pathogenic E. coli strains differ in their virulence factor (VFs) which confer pathogenic potential. Some recognized VFs of pathogenic E. coli include diverse adhesins (e.g., P fimbriae, S and F1C fimbriae), toxins (e.g., hemolysin and cytotoxic necrotizing factor), siderophores (e.g., aerobactin and yersiniabactin), polysaccharide coatings (e.g., group II and group III capsules and lipopolysaccharide), and invasins. These VFs alleviate colonization and invasion of the host, avoidance or disruption of host defense mechanism, and stimulation of inflammatory response [1].

Phylogenetically, strains of E. coli are divided into four groups: A, B1, B2, and D. They can be distinguished upon the presence of chuA and yjaA genes, and TSPE4.C2 noncoding region [2]. Some studies have reported an association of VF genes with phylogenetic group affiliation [1, 3, 4]. Commensal E. coli strains belong mostly to groups A and B1 9130. EHEC, ETEC, and EIEC strains are linked with groups A and B1 [5]. Strains isolated from extraintestinal infections, on the other hand, belong mostly to group $\mathrm{B} 2$ and, to a lesser extent, D [1, 5]. EPEC, EAEC, and DAEC are not associated with phylogenetic group affiliation [5]. The predominance of different phylogroups may also vary due to geographical location, the site of infection, and the level of antibiotic resistance $[6,7]$.

The presence of $E$. coli strains with virulence factors in water environments creates a potential risk of infections in humans due to the use of the water as a source of drinking or for recreation [8-10]. Another risk comes from the antibiotic resistance of the environmental $E$. coli strains. Multiresistant $E$. coli have been reported in river water worldwide [11-15]. An important role in the spread of antibiotic resistance is played by integrons - genetic platforms that are responsible for integration and rearrangements of resistance determinants 
called gene cassettes [16]. They consist of an integrase gene, a primary recombination site called $a t t I$, and a promoter $\mathrm{P}_{\mathrm{C}}$ that directs transcription of the integrated genes. Three classes of integrons, distinguished upon the integrase gene sequences, are responsible for multidrug resistance, with class 1 being most ubiquitous among resistant bacteria and considered to play the main role in the emergence and widespread of resistance genes $[16,17]$. Bacterial strains harboring integrons are usually multiresistant, i.e., resistant to antimicrobials of at least three different classes [12, 18, 19].

Some studies indicated that among clinical E. coli strains, the production of virulence factors is negatively associated with resistance to some antibiotics, including fluoroquinolones [20, 21]. On the other hand, such phenomenon is not observed among isolates of animal origin [20]. This suggests that ecological factors may determine relations between bacterial virulence and antibiotic resistance [20].

Chen et al. [22] have showed that $E$ coli stains isolated from river water can carry both virulence genes and integrons. Little is known, however, about the relation between the occurrence of VF genes and the presence of integrons in environmental $E$. coli isolates. Hence, the aim of this study was to determine the presence of virulence-associated genes and the phylogenetic group affiliation of $E$. coli isolates cultured from river water, with regard to the presence of class 1 integrons.

\section{Materials and Methods}

\section{Bacterial Strains and Class 1 Integrase Presence}

A total of 192 isolates of $E$. coli cultured from the water of the Warta River, Poland, were used in this study. The Warta River runs in central-western Poland and has a length of $808 \mathrm{~km}$. Water samples were collected three times in 2010, at eight stations localized along the river course. The samples were taken at the depth of $0.3 \mathrm{~m}$ and the distance of $1 \mathrm{~m}$ from the riverbank. The samples were then transported to a laboratory at $4{ }^{\circ} \mathrm{C}$ in a temperature-controlled box and analyzed within 8 h. E. coli strains were isolated on Brilliance E. coli/coliform Selective Agar (Oxoid) and identified with API 20E (bioMérieux). The isolates were then checked for the presence of integrase genes in the multiplex PCR assay according to Dillon et al. [23]. Ninety-six unique strains with class 1 integrase gene (intI1) were chosen from a pool of 279 isolates, and 96 integron-negative strains were chosen from a total of 3,417 isolates with the use of Research Randomizer 4.0 random number generator. The strains were selected randomly and proportionally to the number of strains per each sampling site. The strains used in the study were genetically unrelated: they had distinct DNA fingerprinting pattern $(<90 \%$ similarity, i.e., at least one band differing two isolates) determined in ERIC-PCR according to Versalovic et al. [24], followed by computer analysis of gels by using GelCompar II 3.5 software (Applied Maths) with Dice similarity coefficient and UPGMA clustering method.

\section{Analysis of Variable Region of Class 1 Integrons}

The size of the variable regions of class 1 integrons was determined by PCR amplification with primers complementary to their $5^{\prime}$ and $3^{\prime}$ conserved regions [25]. The PCR was conducted as follows: initial denaturation $94{ }^{\circ} \mathrm{C}, 5 \mathrm{~min}$, and 30 cycles of $94{ }^{\circ} \mathrm{C}$ at $1 \mathrm{~min}, 59^{\circ} \mathrm{C}$ at $1 \mathrm{~min}, 72^{\circ} \mathrm{C}$ at $5 \mathrm{~min}$, and final elongation $72{ }^{\circ} \mathrm{C}$ at $8 \mathrm{~min}$. After agarose gel electrophoresis with MassRuler DNA Ladder (Fermentas), the size of the PCR products was determined by using GelCompar II 3.5. The amplicons were then purified with ExoSAP-IT (Affymetrix) and sequenced in a 3100xl Genetic Analyzer (Applied Biosystems). Sequence data were assembled with DNA Baser (HeracleSoftware) and aligned with GenBank data by using nucleotide Basic Local Alignment Search Tool.

\section{Determination of Phylogenetic Groups}

Affiliation of $E$. coli isolates to phylogenetic groups A, B1, $\mathrm{B} 2$, and $\mathrm{D}$, and subgroups $\mathrm{A}_{0}, \mathrm{~A}_{1}, \mathrm{~B} 1, \mathrm{~B} 2_{2}, \mathrm{~B} 2_{3}, \mathrm{D}_{1}$, and $\mathrm{D}_{2}$, was done upon triplex PCR method according to Clermont et al. [2]. The PCR assay applied primers targeting genes chuA and yjaA, and a noncoding region Tspe4.C2. The reaction consisted of initial denaturation for $5 \mathrm{~min}$ at $94{ }^{\circ} \mathrm{C}$ and 30 cycles of $30 \mathrm{~s}$ at $94^{\circ} \mathrm{C}, 30 \mathrm{~s}$ at $55^{\circ} \mathrm{C}$, and $30 \mathrm{~s}$ at $72{ }^{\circ} \mathrm{C}$ followed by a final extension step of $7 \mathrm{~min}$ at $72^{\circ} \mathrm{C}$. The four phylogenetic groups and seven subgroups were distinguished upon the following genotypes: $\mathrm{A}: \mathrm{A}_{0}$, chuA-, yjaA-, Tspe4.C2- and $\mathrm{A}_{1}$, chuA-, yjaA+, Tspe4.C2-; B1, chuA-, yjaA-, Tspe4.C2+; B2:B2 2, chuA+, yjaA+, Tspe4.C2- and $\mathrm{B} 2{ }_{3}, c h u A+, y j a A+$, Tspe4.C2+; D:D $\mathrm{D}_{1}$, chuA+, yjaA-, Tspe4.C2- and $\mathrm{D}_{2}$, chuA+, yjaA-, Tspe4.C2+ [2, 26].

Identification of Genes Associated with Virulence

Multiplex PCR assays according to Aranda et al. [27] were done to detect typical and atypical EPEC, EAEC, ETEC, EIEC, and STEC isolates. The targeted genes were eae and $b f p A$ for EPEC; CVD432 for EAEC; heat-labile (LT) and heat-stable (ST) enterotoxin genes for ETEC; ipaH for EIEC; and stx 1 and stx 2 for STEC.

Virulence genes characteristic for extraintestinal $E$. coli were detected by PCR assays. The following genes were targeted using primers and PCR conditions recommended by Johnson and Stell [1]: fyuA (encoding yersiniabactin 
receptor), iutA (aerobactin receptor gene), hlyA (haemolysin A gene), $p a p A$ ( $\mathrm{P}$ fimbriae subunit gene), sfaS ( $\mathrm{S}$ fimbriae subunit gene), foc $G$ (F1C fimbriae subunit gene), and cnfl (cytotoxic necrotizing factor gene). VF virulence factor gene score was determined as the total number of virulenceassociated genes per strain.

\section{Statistical Analysis}

Association between VF genes and the presence of class 1 integrase gene was determined with Pearson's $\chi^{2}$ test or Fisher's exact test, depending on cell frequencies, with $P<$ 0.05 reflecting statistical significance. For comparisons on the prevalence of VF genes and integrase genes among phylogenetic groups, $P$ value threshold was lowered to $P<$ 0.008 according to Bonferroni's correction for multiple comparisons. Association between VF scores and integron presence was determined with the Mann-Whitney $U$ test. Association between VF scores and phylogenetic groups was established with Kruskal-Wallis test. Calculations were done with Statistica 10 (StatSoft).

\section{Results}

The number of $E$. coli in the water samples taken from the Warta River during isolation of the study material ranged from $4.0 \times 10^{1}$ to $3.6 \times 10^{4} \mathrm{CFU} / 100 \mathrm{ml}$. A total of $192 \mathrm{E}$. coli isolates (96 with class 1 integrons and 96 without integrons) were analyzed for their phylogenetic group affiliation and the presence of virulence-associated genes.

The sizes of the variable regions of the integron-positive isolates ranged between 0.18 and $3.0 \mathrm{kbp}$. Sequence analysis of their content showed that the most frequent gene cassette array was $d$ frAl-aadA1 (50.0\% of the strains) followed by $d$ frA17-aadA5 (15.6\%), aadA1 (13.5\%), dfrA1 (5.2\%), aacA4-aadA1 (3.1\%), dfrA12-orfF-aadA (3.1\%), and aadB-aadA1-cmlA1 (1.0\%). Two strains (2.1\%) had variable regions of $0.18 \mathrm{kbp}$ with no gene cassettes. For six strains $(6.2 \%)$, we did not manage to amplify the variable region. There was no correlation between the size of the integron variable regions and phylogenetic group affiliation and the presence of virulence-associated genes.

The most prevalent phylogenetic group in both intI1positive and intI1-negative isolates was A $(P<0.01)$. However, there was no association between the presence of class 1 integrons and phylogenetic group affiliation. The frequencies of integron-positive and -negative isolates in four major phylogenetic groups were similar, with no statistically significant differences (Table 1).

The presence of virulence-associated genes was determined in a series of PCR assays. Eighty-four (87.5\%) intI1-positive and 53 (55.2\%) intI1-negative isolates carried
Table 1 Phylogenetic group affiliation of integron-positive and -negative E. coli isolates from the Warta river

\begin{tabular}{llll}
\hline Phylogenetic group $(n)$ & \multicolumn{2}{l}{ Class 1 integron presence } & \multirow{2}{*}{$P$ value $^{\mathrm{c}}$} \\
\cline { 2 - 3 } & intI1-positive, \% ${ }^{\mathrm{a}}\left(n^{\mathrm{b}}\right)$ & intIl -negative, \% (n) & \\
\hline A (92) & $45.7(42)$ & $54.3(50)$ & 0.248 \\
$\mathrm{~A}_{0}(23)$ & $34.8(8)$ & $65.2(15)$ & 0.120 \\
$\mathrm{~A}_{1}(69)$ & $49.3(34)$ & $50.7(35)$ & 0.880 \\
$\mathrm{~B} 1(37)$ & $56.8(21)$ & $43.2(16)$ & 0.360 \\
$\mathrm{~B} 2(21)$ & $57.1(12)$ & $42.9(9)$ & 0.488 \\
$\mathrm{~B} 2_{2}(7)$ & $85.7(6)$ & $14.3(1)$ & 0.118 \\
$\mathrm{~B} 2_{3}(14)$ & $42.9(6)$ & $57.1(8)$ & 0.579 \\
$\mathrm{D}(42)$ & $50.0(21)$ & $50.0(21)$ & 1.000 \\
$\mathrm{D}_{1}(24)$ & $33.3(8)$ & $66.7(16)$ & 0.081 \\
$\mathrm{D}_{2}(18)$ & $72.2(13)$ & $27.8(5)$ & 0.081 \\
\hline
\end{tabular}

a Percentage of strains within a phylogenetic group/subgroup

${ }^{\mathrm{b}}$ Number of strains

${ }^{\mathrm{c}} P$ value calculated in Pearson's $\chi^{2}$ test or Fisher's exact test (when cell frequency $\leq 5$ )

at least one virulence gene. The results shown in Table 2 revealed statistically significant differences between integron-positive and -negative $E$. coli isolates in frequencies of heat-stable toxin gene (ST) of enterotoxigenic $E$. coli, S fimbriae subunit gene $s f a S$, and siderophore receptor genes fyuA and iutA. All those genes were found more often in isolates harboring class 1 integrons, regardless of their gene cassette content.

Table 2 Association between prevalence of virulence-associated genes and the presence of integrons in E. coli strains isolated from the Warta river water

\begin{tabular}{llll}
\hline \multirow{2}{*}{ VF gene } & \multicolumn{2}{l}{ Class 1 integron presence } & $P$ \\
\cline { 2 - 3 } & intI1-positive, \% $(n)$ & intI1-negative, \% $(n)$ & \\
\hline eae & $(0)$ & $(0)$ & - \\
bfpA & $(0)$ & $(0)$ & - \\
CVD432 & $(0)$ & $1.0(1)$ & 1.000 \\
LT & $2.1(2)$ & $(0)$ & 0.497 \\
ST & $17.7(17)$ & $1.0(1)$ & $<0.001^{\mathrm{a}}$ \\
stx1 & $5.2(5)$ & $4.2(4)$ & 1.000 \\
stx2 & $3.1(3)$ & $2.1(2)$ & 1.000 \\
ipaH & $7.3(7)$ & $13.6(13)$ & 0.156 \\
fyuA & $50(48)$ & $20.8(20)$ & $<0.001^{\mathrm{a}}$ \\
iutA & $37.5(36)$ & $20.8(20)$ & $0.011^{\mathrm{a}}$ \\
hlyA & $2.1(2)$ & $1.0(1)$ & 1.000 \\
papA & $7.3(7)$ & $2.1(2)$ & 0.169 \\
sfaS & $28.1(27)$ & $12.5(12)$ & $0.007^{\mathrm{a}}$ \\
cnf1 & $2.1(2)$ & $(0)$ & 0.497 \\
focG & $2.1(2)$ & $3.8(3)$ & 1.000 \\
\hline a & & $P$ &
\end{tabular}

${ }^{\text {a }}$ Significant $P$ values ( $\chi^{2}$ or Fisher's exact test) 
The distribution of virulence-associated genes among phylogenetic groups and subgroups was presented in Table 3. The eae and bfpA genes, absent in all isolates, and CVD432, present only in one isolate from B1 group, were excluded from the table. Only the presence of fyuA and iutA genes was associated with phylogenetic group affiliation $(P<0.005)$. The yersiniabactin receptor gene $f y u A$ was most frequent in B2 group (compared to groups A, B1, and D), and the aerobactin receptor gene iutA was more frequent in $\mathrm{B} 2$ group than in $\mathrm{A}$ and B1. Analysis of distribution of VF genes within particular phylogenetic groups showed differences in group B2 in the case of the iutA gene which was more frequent in the subgroup $\mathrm{B} 2_{3}(P=0.017)$, and in group A in the case of the fyuA gene which was more frequent in the subgroup $\mathrm{A}_{1}(P=0.030)$.

Comparison of VF scores of integron-positive and -negative $E$. coli isolates showed that the VF score was associated with the presence of class 1 integrons (Table 4). Comparison of VF scores between intII-positive and intIl-negative isolates within particular phylogenetic groups revealed statistically significant differences in groups A (both subgroups), B1, and D (only subgroup $\mathrm{D}_{1}$ ). On the other hand, VF score was not associated with the gene cassette content of the integrons (Kruskal-Wallis test, $P=0.697$ ).

Kruskal-Wallis analysis of variance showed that VF score was associated with phylogenetic group affiliation $(P=0.009)$ when integron-positive and -negative isolates were taken together. However, when VF scores were compared for intI1-positive and intII-negative isolates separately, statistically significant differences were found only for isolates without integrons $(P=0.001)$. Multiple pairwise comparisons in that group showed that B2 isolates had the highest VF score compared to any other phylogenetic group ( $P=0.004$ vs. group $\mathrm{A}, P=0.003$ vs. group $\mathrm{B} 1$, and $P=0.046$ vs. group D).

\section{Discussion}

Resistance integrons are found frequently among clinical $E$. coli isolates $[28,29]$ and are also present in strains isolated from the environment $[11,13,15,22]$. Class 1 integrons can be considered markers of antimicrobial multiresistance, even regardless of their gene cassette content, as they are often located in transferable plasmids and/or transposons carrying resistance genes $[18,19]$. This also facilitates the spread of resistance not only within the same species but also to other genera [30]. In this study, we analyzed two sets of environmental $E$. coli isolates (with and without class 1 integrons) for their virulence potential and phylogenetic group affiliation. There was no difference in phylogenetic group distribution between isolates with class 1 integrons and those without the integrons. Most of the isolates, regardless of integron presence, belonged to phylogenetic group A, which includes commensal E. coli [1], but also EHEC, ETEC, and EIEC [5]. Group A strains have been also most prevalent among integron-bearing intestinal $E$. coli isolates from healthy subjects without antibiotic exposure [31]. On the other hand, Figueira et al. [32], who have analyzed E. coli isolated from wastewater treatment plant and surface water, found class 1 integrons significantly less prevalent in group A than in the others. Mokracka et al. [3] have reported that groups D and B1 isolates are more frequent in integron-positive $E$. coli (compared to integron-negative isolates) originated from a wastewater treatment plant.

In both intI1-positive and -negative $E$. coli isolates, majority of the strains harbored at least one virulence-associated gene, but they occurred more frequently in integron-positive isolates $(P<0.001)$. One third of integron-positive isolates and $22 \%$ of integron-negative isolates had genes characteristic for diarrheagenic E. coli pathotypes: ETEC, STEC, EAEC, and

Table 3 Distribution of virulence factor genes among $E$. coli isolates of different phylogenetic groups and subgroups

\begin{tabular}{|c|c|c|c|c|c|c|c|c|c|c|c|c|}
\hline \multirow{2}{*}{$\begin{array}{l}\text { Phylogenetic } \\
\text { group/subgroup } \\
(n)\end{array}$} & \multicolumn{12}{|l|}{ VF genes } \\
\hline & LT, $\%^{\mathrm{a}}\left(n^{\mathrm{b}}\right)$ & $\mathrm{ST}, \%(n)$ & $s t x_{1}, \%(n)$ & $s t x_{2}, \%(n)$ & $i p a H, \%(n)$ & fyuA, \% (n) & $i u t A, \%(n)$ & $h l y A, \%(n)$ & papA, \% (n) & $s f a S, \%(n)$ & foc $G, \%(n)$ & $c n f 1, \%(n)$ \\
\hline A (92) & $1.1(1)$ & $9.8(9)$ & $5.4(5)$ & $3.3(3)$ & $12.0(11)$ & $26.1(24)$ & $19.6(18)$ & $1.1(1)$ & $4.3(4)$ & 20.7 (19) & $1.1(1)$ & $2.2 \%(2)$ \\
\hline $\mathrm{A}_{0}(23)$ & $0(0)$ & 8.7 (2) & $4.3(1)$ & $0(0)$ & $17.4(4)$ & $8.7(2)$ & 8.7 (2) & $4.3(1)$ & $0(0)$ & $17.4(4)$ & $0(0)$ & $0(0)$ \\
\hline$A_{1}(69)$ & $1.4(1)$ & $10.1(7)$ & $5.8(4)$ & $4.3(3)$ & $10.1(7)$ & $31.9(22)$ & $23.2(16)$ & $0(0)$ & $5.8(4)$ & $21.7(15)$ & $1.4(1)$ & $2.9(2)$ \\
\hline B1 (37) & $0(0)$ & $16.2(6)$ & $5.4(2)$ & $0(0)$ & $8.1(3)$ & 35.1 (13) & $18.9(7)$ & $2.7(1)$ & $2.7(1)$ & $18.9(7)$ & $0(0)$ & $0(0)$ \\
\hline B2 (21) & $0(0)$ & $4.8(1)$ & $0(0)$ & $0(0)$ & $0(0)$ & $76.2(16)$ & $66.7(14)$ & $0(0)$ & $4.8(1)$ & $33.3(7)$ & $0(0)$ & $4.8(1)$ \\
\hline $\mathrm{B} 2_{2}(7)$ & $0(0)$ & $0(0)$ & $0(0)$ & $0(0)$ & $0(0)$ & $71.4(5)$ & $28.6(2)$ & $0(0)$ & $0(0)$ & $14.3(1)$ & $0(0)$ & $0(0)$ \\
\hline $\mathrm{B} 2_{3}(14)$ & $0(0)$ & $7.1(1)$ & $0(0)$ & $0(0)$ & $0(0)$ & $78.6(11)$ & $85.7(12)$ & $0(0)$ & $7.1(1)$ & $42.3(6)$ & $0(0)$ & $7.1(1)$ \\
\hline D (42) & $2.4(1)$ & $4.8(2)$ & $4.8(2)$ & $4.8(2)$ & $14.3(6)$ & $35.7(15)$ & $40.5(17)$ & $2.4(1)$ & $7.1(3)$ & $14.3(6)$ & $2.4(1)$ & $4.8(2)$ \\
\hline $\mathrm{D}_{1}(24)$ & $0(0)$ & $8.3(2)$ & $(0)$ & $0(0)$ & $8.3(2)$ & $33.3(8)$ & $37.5(9)$ & $0(0)$ & $4.2(1)$ & $16.7(4)$ & $0(0)$ & $8.3(2)$ \\
\hline $\mathrm{D}_{2}(18)$ & $5.6(1)$ & (0) & $11.1(2)$ & $11.1(2)$ & $22.2(4)$ & $38.9(7)$ & $44.4(8)$ & $5.6(1)$ & $11.1(2)$ & $11.1(2)$ & $5.6(1)$ & $0(0)$ \\
\hline
\end{tabular}

${ }^{\text {a }}$ Percentage of strains within a phylogenetic group/subgroup

${ }^{b}$ Number of strains 
Table 4 VF scores of integron-positive and integron-negative $E$. coli in relation to phylogenetic group affiliation

\begin{tabular}{|c|c|c|c|c|c|c|c|}
\hline \multirow{2}{*}{$\begin{array}{l}\text { Phylogenetic } \\
\text { group/subgroup }\end{array}$} & \multicolumn{2}{|l|}{ VF score range } & \multicolumn{2}{|c|}{ Median VF score } & \multicolumn{2}{|c|}{ Average VF score } & \multirow[t]{2}{*}{$P$} \\
\hline & intI1-positive & intI1-negative & intI1-positive & intI1-negative & intI1-positive & intI1-negative & \\
\hline A & $0-4$ & $0-3$ & 1 & 1 & 1.52 & 0.68 & $<0.001^{c}$ \\
\hline $\mathrm{A}_{0}$ & $1-3$ & $0-1$ & 1 & 0 & 1.38 & 0.33 & $0.004^{\mathrm{a}}$ \\
\hline $\mathrm{A}_{1}$ & $0-4$ & $0-3$ & 1 & 1 & 1.56 & 0.83 & $0.015^{\mathrm{a}}$ \\
\hline B1 & $0-3$ & $0-2$ & 1 & 0 & 1.57 & 0.50 & $0.003^{\mathrm{a}}$ \\
\hline B2 & $0-3$ & $1-4$ & 1.5 & 2 & 1.75 & 2.11 & 0.522 \\
\hline $\mathrm{B} 2_{2}$ & $0-3$ & 1 & 1 & 1 & 1.17 & 1.00 & 1.000 \\
\hline $\mathrm{B} 2_{3}$ & $1-3$ & $1-4$ & 2.5 & 2 & 2.33 & 2.25 & 0.846 \\
\hline $\mathrm{D}$ & $0-5$ & $0-3$ & 1 & 1 & 1.90 & 0.86 & $0.008^{\mathrm{a}}$ \\
\hline $\mathrm{D}_{1}$ & $0-4$ & $0-2$ & 2 & 0.5 & 2.12 & 0.69 & $0.011^{\mathrm{a}}$ \\
\hline $\mathrm{D}_{2}$ & $1-5$ & $0-3$ & 1 & 1 & 1.77 & 1.40 & 0.767 \\
\hline Total & $0-5$ & $0-4$ & 1 & 1 & 1.65 & 0.82 & $<0.001^{\circ}$ \\
\hline
\end{tabular}

${ }^{\text {a }}$ Statistically significant differences between intI1-positive and intI1-negative isolates (Mann-Whitney $U$ test)

EIEC. The presence of diarrheagenic $E$. coli in river water have been reported by Loukiadis at al. [33], who found STEC and EPEC isolates in French rivers in sampling points located upstream and downstream of the effluent discharges of slaughterhouses. STEC genes have been also found in recreational waters in Argentina [34], whereas EAEC and atypical EPEC were isolated from St. Clair River and Detroit River areas [8].

Four genes, the heat-stable toxin gene of enterotoxigenic $E$. coli, S fimbriae subunit gene $s f a S$, and siderophore receptor genes fyuA and iutA, were associated with the presence of class 1 integrons, whereas none of the genes investigated occurred more frequently in the intI1-negative isolates. This may suggest that at least in some cases, those virulence genes were localized within the same plasmids as the integrons. Moreover, VF scores, which reflect pathogenic potential of strains, were also higher in integron-bearing isolates. VF scores were also associated with phylogenetic group affiliation when both integron-positive and -negative isolates were pooled together. Interestingly, this association was due to significantly higher VF scores of subroup $\mathrm{B} 2_{3}$ integronnegative isolates and was absent in strains with class 1 integrons. It is worth to note that $\mathrm{B} 2_{3}$ strains originate from human and have not been found in animal feces [35].

The variable region of the integrons showed little diversity. Only five different gene cassette arrays were detected. Half of the strains had integrons with $d$ frAl-aadAl gene cassette array. These genes code for dihydrofolate reductase conferring resistance to trimethoprim and aminoglycoside adenylyltransferase conferring resistance to aminoglycosides, respectively. Two isolates had "empty" integron with no incorporated gene cassettes, and we did not manage to amplify the variable region for six strains, which suggests altered sequence or the lack of sull gene in the $3{ }^{\prime}$ conserved region [13].
Subgroups $\mathrm{B} 2_{2}$ and $\mathrm{B} 2_{3}$ showed heterogeneity when it comes to the presence of iutA $(P=0.017)$, whereas $\mathrm{A}_{0}$ and $\mathrm{A}_{1}$ differed in the frequency of the $f y u A$ gene $(P=0.030)$. These genes code for aerobactin- and yersiniabactin-mediated iron acquisition systems, respectively, and are frequent among clinical E. coli isolates $[1,20,36]$.

This paper reports a relationship between integrons, phylogenetic groups, and virulence traits in E. coli isolated from river water. We showed that, in E. coli isolates originated from river water, (a) the presence of class 1 integrons, regardless of their gene cassette content, was positively associated with the presence and the number of virulence genes; (b) the presence of class 1 integrons was not associated with phylogenetic group affiliation; and (c) the number of virulence genes was associated with phylogenetic group affiliation. Environmental water habitats, especially rivers and streams, are ideal vectors for the antibiotic resistance dissemination [37]. Virulence-associated genes are often located in plasmids or pathogenicity islands. Simultaneous presence of VF genes and class 1 integrons enhances possibility of spreading both virulence traits and antibiotic resistance via horizontal gene transfer. This may lead to ecological changes and predomination of virulent, antibiotic-resistant bacteria in the environment.

Acknowledgments This work was partially supported by grant (no. N N305 035337) from the Polish Ministry of Science and Higher Education.

Open Access This article is distributed under the terms of the Creative Commons Attribution License which permits any use, distribution, and reproduction in any medium, provided the original author(s) and the source are credited. 


\section{References}

1. Johnson JR, Stell AL (2000) Extended virulence genotypes of Escherichia coli strains from patients with urosepsis in relation to phylogeny and host compromise. J Infect Dis 181:261-272

2. Clermont O, Bonacorsi S, Bingen E (2000) Rapid and simple determination of the Escherichia coli phylogenetic group. Appl Environ Microbiol 66:4555-4558

3. Mokracka J, Koczura R, Jabłońska L, Kaznowski A (2011) Phylogenetic groups, virulence genes and quinolone resistance of integron-bearing Escherichia coli strains isolated from a wastewater treatment plant. Antonie van Leeuwenhoek 99:817-824

4. Obeng AS, Rickard H, Ndi O, Sexton M, Barton M (2012) Antibiotic resistance, phylogenetic grouping and virulence potential of Escherichia coli isolated from the faeces of intensively farmed and free range poultry. Vet Microbiol 154:305-315

5. Escobar-Páramo P, Clermont O, Blanc-Potard AB, Bui H, Le Bouguénec C, Denamur E (2004) A specific genetic background is required for acquisition and expression of virulence factors in Escherichia coli. Mol Biol Evol 21:1085-1094

6. Bukh AS, Schønheyder HC, Emmersen JMG, Søgaard M, Bastholm S, Roslev P (2009) Escherichia coli phylogenetic groups are associated with site of infection and level of antibiotic resistance in community-acquired bacteraemia: a 10 year population-based study in Denmark. J Antimicrob Chemother 64:163-168

7. Duriez P, Clermont O, Bonacorsi S, Bingen E, Chaventre A, Elion J, Picard B, Denamur E (2001) Commensal Escherichia coli isolates are phylogenetically distributed among geographically distinct human populations. Microbiology 147:1671-1676

8. Hamelin K, Bruant G, El-Shaarawi A, Hill S, Edge TA, Fairbrother J, Harel J, Maynard C, Masson L, Brousseau R (2007) Occurrence of virulence and antimicrobial resistance genes in Escherichia coli isolates from different aquatic ecosystems within the St. Clair River and Detroit River areas. Appl Environ Microbiol 73:477484

9. Hamner S, Broadaway SC, Mishra VB, Tripathi A, Mishra RK, Pulcini E, Pyle BH, Ford TE (2007) Isolation of potentially pathogenic Escherichia coli O157:H7 from the Ganges River. Appl Environ Microbiol 73:2369-2372

10. Savvaidis I, Kegos T, Papagiannis C, Voidarou C, Tsiotsias A, Maipa V, Kalfakakou V, Evangelou A, Bezirtzoglou E (2001) Bacterial indicators and metal ions in high mountain lake waters. Microb Ecol Health Dis 13:147-152

11. Alexopoulos A, Voidarou C, Stefanis C, Papadopoulos I, Vavias S, Tsiotsias A, Kalkani E, Charvalos E, Bezirtzoglou E (2006) Antibiotic resistance profiles and integrons in Enterobacteriaceae from the riverside of Evros-Ardas with respect to chemical and waste pollution. Microb Ecol Health Dis 18:170-176

12. Koczura R, Mokracka J, Jabłońska L, Gozdecka E, Kubek M, Kaznowski A (2012) Antimicrobial resistance of integronharboring Escherichia coli isolates from clinical samples, wastewater treatment plant and river water. Sci Total Environ 414:680 685

13. Laroche E, Pawlak B, Berthe T, Skurnik D, Petit F (2009) Occurrence of antibiotic resistance and class 1,2 and 3 integrons in Escherichia coli isolated from a densely populated estuary (Seine, France). FEMS Microbiol Ecol 68:118-130

14. Mukherjee S, Chakraborty R (2006) Incidence of class 1 integrons in multiple antibiotic-resistant Gram-negative copiotrophic bacteria from the River Torsa in India. Res Microbiol 157:220-226

15. Ozgumus OB, Sandalli C, Sevim A, Celik-Sevim E, Sivri N (2009) Class 1 and class 2 integrons and plasmid-mediated antibiotic resistance in coliforms isolated from ten rivers in northern Turkey. J Microbiol 47:19-27
16. Cambray G, Guerout A, Mazel D (2010) Integrons. Annu Rev Gen 44:141-166

17. Nemergut DR, Robeson MS, Kysela RF, Martin AP, Schmidt SK, Knight R (2008) Insights and inferences about integron evolution from genomic data. BMC Genomics 9:261

18. Leverstein-van Hall MA, Blok HEM, Rogier A, Donders T, Paauw A, Fluit AC, Verhoef J (2003) Multidrug resistance among Enterobacteriaceae is strongly associated with the presence of integrons and is independent of species or isolate origin. J Infect Dis 187:251-259

19. Mokracka J, Koczura R, Pawłowski K, Kaznowski A (2011) Resistance patterns and integron cassette arrays of Enterobacter cloacae complex strains of human origin. J Med Microbiol 60:737-743

20. Johnson JR, Kuskowski MA, Owens K, Gajewski A, Winokur PL (2003) Phylogenetic origin and virulence genotype in relation to resistance to fluoroquinolones and/or extendedspectrum cephalosporins and cephamycins among Escherichia coli isolates from animals and humans. J Infect Dis 188:759768

21. Kawamura-Sato K, Yoshida R, Shibayama K, Ohta M (2010) Virulence genes, quinolone and fluoroquinolone resistance, and phylogenetic background of uropathogenic Escherichia coli strains isolated in Japan. Jpn J Infect Dis 63:113-115

22. Chen B, Zheng W, Yu Y, Huang W, Zheng S, Zhang Y, Guan X, Zhuang Y, Chen N, Topp E (2011) Class 1 integrons, selected virulence genes, and antibiotic resistance in Escherichia coli isolates from the Minjiang River, Fujian Province, Chian. Appl Environ Microbiol 77:148-155

23. Dillon B, Thomas L, Mohmand G, Zelynsky A, Iredell J (2005) Multiplex PCR for screening of integrons in bacterial lysates. J Microbiol Methods 62:221-232

24. Versalovic J, Koeuth T, Lupski JR (1991) Distribution of repetitive DNA sequences in eubacteria and application to fingerprinting of bacterial genomes. Nucleic Acids Res 19:6823-6831

25. Lévesque C, Piché L, Larose C, Roy PH (1995) PCR mapping of integrons reveals several novel combinations of resistance genes. Antimicrob Agents Chemother 39:185-191

26. Escobar-Páramo P, Grenet K, Le Menac'h A, Rode L, Salgado E, Amorin C, Gouriou S, Picard B, Rahimy MC, Andremont A, Denamur E, Ruimy R (2004) Large-scale population structure of human commensal Escherichia coli isolates. Appl Environ Microbiol 70:5698-5700

27. Aranda KRS, Fagundes-Neto U, Scaletsky ICA (2004) Evaluation of multiplex PCRs for diagnosis of infection with diarrheagenic Escherichia coli and Shigella spp. J Clin Microbiol 42:5849-5853

28. Gu B, Pan S, Wang T, Zhao W, Mei Y, Huang P, Tong M (2008) Novel cassette arrays of integrons in clinical strains of Enterobacteriaceae in China. Int J Antimicrob Agents 32:529-533

29. Vinué L, Sáenz Y, Rojo-Bezares B, Olarte I, Undabeitia E, Somalo S, Zarazaga M, Torres C (2010) Genetic environment of sul genes and characterisation of integrons in Escherichia coli isolates of blood origin in a Spanish hospital. Int J Antimicrob Agents 35:492-496

30. Mokracka J, Koczura R, Kaznowski A (2012) Multiresistant Enterobacteriaceae with class 1 and class 2 integrons in a municipal wastewater treatment plant. Water Res 46:33533363

31. Skurnik D, Lacheeb S, Bernede C, le Menac'H A, Elbaz S, Mohler J, Denamur E, Andremont A, Ruimy R (2009) Integrons and antibiotic resistance in phylogenetic group B2 Escherichia coli. Microb Drug Resist 15:173-178

32. Figueira V, Serra E, Manaia C (2011) Differential patterns of antimicrobial resistance in population subsets of Escherichia coli 
isolated from waste and surface waters. Sci Total Environ 409:1017-1023

33. Loukiadis E, Kérourédan M, Beutin L, Oswald E, Brugère H (2006) Characterization of Shiga toxin gene (stx)-positive and intimin gene (eae)-positive Escherichia coli isolates from wastewater of slaughterhouses in France. Appl Environ Microbiol 72:3245-3251

34. Marucci PL, Olivera NL, Brugnoni LI, Sica MG, Cubitto AM (2010) The occurrence of Shiga toxin-producing Escherichia coli in bathing water of the Sierra de la Ventana region. Buenos Aires Province, Argentina. Environ Monit Assess 175:1-8
35. Carlos C, Pires MM, Stoppe NC, Hachich EM, Sato MI, Gomes TA, Amaral LA, Ottoboni LM (2010) Escherichia coli phylogenetic group determination and its application in the identification of the major animal source of fecal contamination. BMC Microbiol 10:161

36. Koczura R, Kaznowski A (2003) The Yersinia highpathogenicity island and iron-uptake systems in clinical isolates of Escherichia coli. J Med Microbiol 52:637-642

37. Lupo A, Coyne S, Beredonk TA (2012) Origin and evolution of antibiotic resistance: the common mechanisms of emergence and spread in water bodies. Front Microbiol 3:18 